\title{
Palyatif Bakım Servisindeki Yaşlı Hastalarda Polifarmasi ve Uygunsuz İlaç Kullanımının Beers ve TIME-to-STOP Kriterlerine Göre Değerlendirilmesi
}

\author{
Sedat ÇELİKÇI
}

Kestel Devlet Hastanesi, İç Hastalıkları Kliniği, Kestel, Bursa.

\begin{abstract}
ÖZET
Kırılgan yaşlı popülasyondaki uygunsuz ilaçları belirleyerek farkındalık oluşturup klinisyenlere yol gösterici olması açısından bu çalışma planlandı. Retrospektif dosya taraması olarak planlanan çalışmamızda 65 yaş üzeri palyatif bakım ünitesine kabul edilen hastaların başvuru esnasında kullandıkları ilaçların TIME-to-STOP ve Beers kriterlerine göre değerlendirmesi yapılarak hastalardaki uygunsuz ilaç kullanım oranı değerlendirildi. Hastanemizde yatırılarak takip ve tedavisi yapılan 65 yaș üzeri 100 hasta dahil edildi. Hastaların yatıș esnasındaki tanısı, yaş ve cinsiyeti, tıbbi özgeçmişi, kronik hastalıkları, düzenli olarak kullandıkları ilaçlar hastane elektronik arşivi üzerinden tarandı. Elde edilen ilaç preparat isimleri farmakolojik gruplara ayrılarak tek tek TIME-to-STOP ve Beers kriterlerine uygunluk açısından incelendi. Polifarmasi alan hasta oranının $\% 47$ olduğu gözlendi. Beers kriterlerine göre potansiyel uygunsuz ilaç oranı \%8,3 olarak saptandı. TIME-toSTOP kriterlerine göre yapılan değerlendirmede potansiyel uygunsuz ilaç oranı $\% 11,7$ bulundu. Yaşlı, kırılgan bir hasta grubunun değerlendirildiği bu çalışmada polifarmasinin potansiyel uygunsuz ilaç kullanımını artırabileceği görüldü. Dolayısıyla kırılgan bir popülasyonu içeren yaşı hasta grubunda polifarmasiden kaçınılmalı eğer endikasyon dahilinde ilaç reçete ediliyorsa hasta uyumunu arttırmak için muhakkak ilaç kullanımıyla ilgili eğitim verilmelidir.
\end{abstract}

Anahtar Kelimeler: Polifarmasi. Uygunsuz ilaç. Beers kriterleri. TIME-to-STOP. Palyatif bakım. Yaşıı hasta.

Evaluation of Polypharmacy and Potentially Inappropriate Drug Use in Elderly Patients in the Palliative Care Service by Beers and TIME-to-STOP Criteria

\begin{abstract}
This study was planned in order to raise awareness by identifying inappropriate drugs in the fragile elderly population and to guide clinicians. Our study as a retrospective file scan study, included 100 patients over the age of 65 who were followed up and treated in our hospital. The diagnosis, age and sex, medical history, chronic diseases, and medications they regularly use during hospitalization were scanned through the hospital electronic archive. The obtained drug preparation names were divided into pharmacological groups and examined one by one for compliance with TIME-to-STOP and Beers criteria. It was observed that the rate of patients who underwent polypharmacy was $47 \%$. The mean number of drugs used by the patients was found to be 4,7 . Potentially inappropriate drug rate was determined as $8.3 \%$ according to Beers criteria. In the evaluation made according to the TIME-to-STOP criteria, the rate of potentially inappropriate drugs was found to be $11,7 \%$. It was observed that there was a common drug group proton pump inhibitors in both groups. In this study, which evaluated a frail elderly patient group, it was seen that polypharmacy could increase the potential inappropriate drug use. Therefore, polypharmacy should be avoided in the geriatric patient group, which includes a fragile population, and if medication is prescribed within the indication, training on drug use should be given to increase patient compliance.
\end{abstract}

Key Words: Polypharmacy. Potentially inapropriate medication. Beers criteria. TIME-to-STOP. Palliative care.

Gelis Tarihi: 08.Ağustos.2021

Kabul Tarihi: 22.Kasım.2021

Dr. Sedat ÇELIKÇi

Kestel Devlet Hastanesi, İç Hastalıkları Kliniği,

Kestel, Bursa.

Tel: 05514029865

E-posta: sedatcelikci@gmail.com

Yazarların ORCID Bilgileri:

Sedat ÇELIKÇCi: 0000-0002-9731-1424
Son yüzyılda tıp alanındaki gelişmelere bağlı olarak bulaşıcı hastalıkların oranında ve doğum oranlarındaki azalma ile birlikte yaşlı nüfusunda artış olmuştur. Bu durum ekonomik gelişim ve tıbbi tedavi olanaklarına ulaşımın artışıyla birlikte dünya genelinde olduğu gibi ülkemizde de son 30 yılda yaşlı nüfusun toplam nüfusa oranı katlanarak artmıştır. Türkiye'deki 65 yaş ve üzeri yaşlı nüfusun toplam nüfusa oranı 2000 yılında \%5,7 iken, 2020 yılında \%9,5'a yükselmiştir ve 2050 yılında \%20'nin üzerine çıkacağı öngörülmektedir ${ }^{1}$. Tüm dünyada yaşlı nüfusun artması son yılların en önemli demografik olgularından birini oluşturmaktadir ${ }^{2}$. 
Türkiye'deki 65 yaș ve üzeri popülasyonun \%90'ının 1, \%35'inin 2, \%23'ünün 3, \%15'inin ise 4 veya daha fazla kronik hastalığa sahip olduğu bildirilmiştir ${ }^{3}$. Çoklu ilaç kullanımı ya da eş zamanlı olarak birden fazla endikasyon için çok sayıda ilaç kullanımı polifarmasi olarak tanımlanmaktadır ${ }^{4}$. Polifarmasiyi tanımlarken kullanılan ilaç sayısı kaynaklara göre değişiklik göstermekle beraber genellikle günlük en az 5 ilacın kullanımı olarak kabul edilmektedir ${ }^{5}$. Yaşlanma ile birlikte metabolik değişiklikler ve azalmış ilaç klirensi yanısıra polifarmasi de potansiyel olumsuz ilaç-ilaç etkileşimlerini arttırarak advers etkiler görülmesine sebep olabilir.

Türkiye'de palyatif bakım merkezi sayısı ve deneyimi yetersizdir ${ }^{6}$. Türkiye'deki veriler net olmamakla birlikte ABD'deki veriler değerlendirildiğinde 65 yaş ve üzeri palyatif bakım üniteleri ve hospislerde kalan kanser harici hastaların median kalış süresi 114 gün olarak saptanmıştır ${ }^{7}$. Palyatif bakım ünitelerindeki yaşlıların ilaç tedavilerinin düzenlenmesi bu kişilerin bakımının önemli bir parçasıdır. Palyatif bakım ünitelerine alınan hastalar komorbiditesi sebebiyle çoklu ilaç kullanan, düşük yaşam kalitesine sahip ve reçetelenen ilaçlara uyumsuzluk gösteren hasta grubunu oluşturmaktadır. Advers olayların yanı sıra bu tür ilaçların reçetelenmesi önemli ölçüde sağlık harcamasına da sebep olmaktadır ${ }^{8}$. Dolayısıyla palyatif bakım ünitelerindeki yaşlılarda bakımın ve tedavi sürecinin iyileştirilmesi için polifarmasi ve potansiyel uygunsuz ilaç kullanımı ile ilgili kavramları tanımlamak ve gerekli önlemlerin alınması gerekir. Palyatif bakım ünitesinde ömrünün son aylarını geçiren kırılgan yaşlı bir hastanın tedavisinin yeniden değerlendirilmesi ve mümkünse uygunsuz olabilecek bazı ilaçlarının (örneğin primer koruma için kullanılan lipid düşürücü ilaçlar, bazı nörolojik ilaçlar) kesilmesi gerekir. Bu gruba ilaç reçetelenmesi, kullanılan ilaçların düzenlenmesi ve gerekirse kesilmesi ile ilgili birinci basamak sağlık kuruluşlarından başlayarak her kademedeki hekimin üzerinde hassas bir şekilde düşünerek karar vermesi gerekir. Bu konuda klinisyenlere yardımcı olmak için yaşlıda uygunsuz ilaç kullanımını değerlendiren çok sayıda kaynak olmakla birlikte bu konuda özellikle palyatif bakım ünitelerindeki kırılgan yaşlıları değerlendiren kılavuz sayısı sınırlıdır. TIME-to-STOP çalışması, 65 yaş üzeri popülasyon için Türkiye pazarında kullanılan ilaçlara göre 2020 yılında hazırlanmış potansiyel uygunsuz ilaç önerilerini içeren kapsamlı bir kılavuz olarak karşımıza çıkmaktadır? ${ }^{9}$ Yaşlılarda uygunsuz ilaç kullanımının ve olası advers etkilerin önlenmesi açısından oluşturulan Beers kriterleri ise bu konuda ortaya konulmuş ilk kılavuz niteliğindeki çalışmadır. Yeni bulgular ve üretilen yeni ilaçlar dikkate alınarak Beers kriterleri yıllar içerisinde çeşitli revizyonlar geçirmiş ve en son Amerikan Geriatri Cemiyeti tarafından 2019 yılında güncellenmiştir ${ }^{10}$.
Retrospektif dosya taraması olarak planlanan çalışmamızda 65 yaş ve üzeri palyatif bakım ünitesine kabul edilen hastaların başvuru esnasında kullandıkları ilaçların TIME-to-STOP ve Beers kriterlerine göre değerlendirmesi yapılarak hastalardaki uygunsuz ilaç kullanım oranları değerlendirildi.

\section{Gereç ve Yöntem}

Retrospektif dosya taraması olarak planladığımız çalışmamıza, hastanemizin palyatif bakım ünitesinde 1 Haziran 2019- 31 Ocak 2021 tarihleri arasında yatır1larak takip ve tedavisi yapılan 65 yaş üzeri 100 hasta dahil edildi. Hastaların başvuru esnasında reçeteli olarak kullandığı ilaçları tarandı. Hastaların yatış esnasındaki tanısı, yaş ve cinsiyeti, tıbbi özgeçmişi, kronik hastalıkları, düzenli olarak kullandıkları ilaçlar hastane elektronik arşivi üzerinden tarandı. Beş ve üzerinde ilaç kullanımı polifarmasi olarak değerlendirildi. Elde edilen ilaç preparat isimleri farmakolojik gruplara ayrilarak tek tek TIME-to-STOP ve Beers kriterlerine uygunluk açısından incelendi. Çıkan sonuçlardan her iki kılavuza göre ayrı ayrı potansiyel uygunsuz ilaç oranları ve en sık kullanılan uygunsuz ilaç grupları belirlendi.

Bu çalışma Eskişehir Osmangazi Üniversitesi girişimsel olmayan klinik araştırmalar etik kurulundan E25403353-050.99-208223 say1s1 ve 2021-215 karar onayı alınarak yapılmıştır.

Tüm veriler SPSS 23 version software (SPSS Inc, Chicago, IL) kullanılarak analiz edildi. Veriler dağılım yapısına göre ortalama \pm standart sapma, sayı (n) ve yüzde (\%) olarak belirtilmiştir. Polifarmasi ve potansiyel uygunsuz ilaç kullanımı arasındaki ilişkiyi değerlendirmek için ki kare testi uygulandı. P değeri $<0.05$ istatistiksel olarak anlamlı kabul edildi.

\section{Bulgular}

Hastalar 47 erkek ve 53 kadından oluşmaktaydı ve yaş ortalaması $80 \pm 8,1$ (en küçük yaş: 65 en büyük yaş: 96) idi. Tıbbi özgeçmişleri incelendiğinde sahip oldukları kronik hastalıklar Tablo I'de listelenmiştir. Buna göre hastaların 23'ünde çeşitli orijinlere sahip evre 4 maligniteler vardı. Hastaların 22'sinde endokrinolojik hastalıklar (Tip 2 diyabetes mellitus, hipotiroidi), 47'sinde hipertansiyon, 25'inde kardiyovasküler hastalıklar (koroner arter hastalığ 1 , kalp yetmezliği, atriyal fibrilasyon), 53'ünde çeşitli nörolojik hastalıklar (Serebrovasküler hastalık, Parkinson hastalığ1, Alzheimer hastalığı, demans, epilepsi), 25'inde ise solunum sistemi hastalıkları (Astım, KOAH) vardı. Mevcut hastalıklarla ilişsili olarak hastaların düzenli olarak kullandığı toplam 564 ilaç değerlendirildi. Hastalar kullandıkları ilaç sayısına göre değerlendirildiklerinde 0-4 ilaç kullanan hasta sayısı 53 iken, 5 ve 


\section{Yaşılılarda Polifarmasi ve Uygunsuz İlaç Kullanımı}

üzeri ilaç kullanan hasta sayısının 47 olduğu gözlendi. Hastaların kullandığı ortalama ilaç sayısı 4,7 $\pm 2,4$ (minimum: 1, maksimum: 11) bulundu. Beers kriterlerine göre 564 ilaç içerisinde potansiyel uygunsuz ilaç oranı \%8,3 olarak saptand1. Beers kriterlerine göre değerlendirilen potansiyel uygunsuz ilaçlar Tablo II'de listelenmiştir. Proton pompa inhibitörleri en sık kullanılan (n: 33) potansiyel uygunsuz ilaç olarak bulundu. Diğer kullanılan potansiyel uygunsuz ilaçlar; metoklopramid (n: 6), nonsteroid antiinflamatuar ilaçlar (NSAIII) (n: 4), doksazosin (n: 2), benzodiyazepin (n: 1) ve megestrol (n: 1) idi. TIME-to-STOP kriterlerine göre yapılan değerlendirmede 564 ilaç içerisinde potansiyel uygunsuz ilaç oranı \%11,7 bulundu. TIME-to-STOP kriterlerine göre değerlendirilen potansiyel uygunsuz ilaçlar Tablo III'te listelenmiştir. Bu grupta da ilk sırada proton pompa inhibitörleri (n: 33) yer alıyordu. Diğerleri furosemid (n: 10), metoklopramid (n: 6), NSAIİ (n: 4), nitrat (n: 3), pirasetam (n: 3), trimetazidin (n: 2), doksazosin (n: 2), teofilin (n: 2), benzodiyazepin (n: 1), megestrol (n: 1), karbamazepin (n: 1) idi. Her iki grupta da ortak olarak en sık kullanılan ilaç grubunun proton pompa inhibitörleri olduğu gözlendi. TIME-to-STOP kriterlerine göre potansiyel uygunsuz ilaç kullanan hasta sayısı ile polifarmasi kullanımı arasında istastiski olarak anlamlilık saptand $1(\mathrm{p}<0.05)$. TIME-to-STOP kriterlerine göre değerlendirildiğinde polifarmasiye maruz kalan hastaların her birinin en az bir adet potansiyel uygunsuz ilaç kullandığı saptandı.

Tablo I. Kronik hastalıkların dağılımı

\begin{tabular}{|l|c|}
\hline Kronik hastalıklar & Hasta sayısı (n=100) \\
\hline Endokrinolojik hastalıklar & 22 \\
Tip 2 DM & 20 \\
Hipotiroidi & 2 \\
\hline Santral Sinir Sistemi hastalıkları & 53 \\
Serebrovasküler hastalık & 23 \\
Alzheimer hastalığı & 23 \\
Demans & 11 \\
Parkinson hastalığı & 6 \\
Epilepsi & 1 \\
\hline Kardiyovasküler sistem hastalıkları & 58 \\
Hipertansiyon & 47 \\
Koroner arter hastalığı & 7 \\
Atriyal fibrilasyon & 4 \\
Kalp yetmezliği & 25 \\
\hline Evre 4 malignite & 23 \\
\hline Astım/KOAH & 25 \\
\hline
\end{tabular}

Tablo II. Beers kriterlerine göre hastaların kullandıkları potansiyel uygunsuz ilaçlar

\begin{tabular}{|l|c|}
\hline \multicolumn{1}{|c|}{$\begin{array}{c}\text { Kullanılan ilaç } \\
\text { etken maddeleri }\end{array}$} & $\begin{array}{c}\text { Kullanılan ilaç sayısı } \\
(\mathbf{n}=\mathbf{4 7})\end{array}$ \\
\hline Proton pompa inhibitörleri & $33(\% 70)$ \\
Metoklopramid & $6(\% 13)$ \\
NSAii & $4(\% 9)$ \\
Doksazosin & $2(\% 4)$ \\
Benzodiyazepin & $1(\% 2)$ \\
Megestrol & $1(\% 2)$ \\
\hline
\end{tabular}

Tablo III. TIME-to-STOP kriterlerine göre hastaların kullandıkları potansiyel uygunsuz ilaçlar

\begin{tabular}{|l|c|}
\hline \multicolumn{1}{|c|}{$\begin{array}{c}\text { Kullanılan ilaç } \\
\text { etken maddeleri }\end{array}$} & $\begin{array}{c}\text { Kullanılan ilaç sayısı } \\
\text { ( } \mathbf{n}=66)\end{array}$ \\
\hline Proton pompa inhibitörleri & $33(\% 50)$ \\
Furosemid & $10(\% 15)$ \\
Metoklopramid & $6(\% 9)$ \\
NSAil & $4(\% 6)$ \\
Nitrat & $3(\% 4)$ \\
Pirasetam & $3(\% 4)$ \\
Trimetazidin & $2(\% 3)$ \\
Doksazosin & $2(\% 3)$ \\
Teofilin & $2(\% 3)$ \\
Benzodiyazepin & $1(\% 1)$ \\
Megestrol & $1(\% 1)$ \\
Karbamazepin & $1(\% 1)$ \\
\hline
\end{tabular}

\section{Tartışma}

Polifarmasi ve potansiyel uygunsuz ilaç kullanımı sıklığı ve ilişkisinin değerlendirildiği çalışmamızda palyatif bakım ünitesinde yatan yaşlı hastaların büyük bir kısmında kronik hastalıkları dolayısıyla polifarmasi olduğu gözlendi. Öncelikle polifarmasiye bir sebep olarak kronik hastalıklar olabileceği düşünüldü ancak sonradan görüldü ki proton pompa inhibitörleri gibi bazı ilaçlar herhangi bir dispeptik yakınması olmamasına rağmen çoklu ilaç kullanan hastalarda sıkça reçetelenmekteydi. Diğer yönden akut hadiselerde kullanılan metoklopramid ve NSAIII gibi ilaçlar hasta veya yakınları tarafindan tekrar tekrar temin edilerek rutin bir şekilde günlük olarak kullanılmaktaydı. Bu iki durum da akılcı ilaç kullanımının önemini bir kez daha göstermiştir. Örneğin endikasyon olmadan 8 haftadan uzun proton pompa inhibitörlerinin kullanımı 2015 Beers kriterlerinde belirtildiği üzere bakteriyel aşırı çoğalma ve clostridium difficile enfeksiyonlarında artışa ve kemik mineral yoğunluğunda azalmaya bağlı olarak kemik fraktürlerinde artışa sebep olabilir ${ }^{11}$. Proton pompa inhibitörlerinin endikasyon olmadan reçetelendiği birçok çalışmada dikkati çekmekte$\operatorname{dir}^{11-13}$. Benzer şekilde geçerli bir endikasyon olmadan kullanılan metoklopramid ekstrapiramidal semptomlara sebep olabileceği gibi kronik NSAIII kullanımında da gastrointestinal hemorajiler görülebilmektedir ${ }^{14}$.

Her iki kritere göre potansiyel uygunsuz ilaç kullanım oranlarına bakıldığında TIME-to-STOP kriterlerine göre oranın daha yüksek olduğu görüldü. Bunun önemli bir sebebi olarak Beers kriterlerinin Amerika Birleşik Devletleri'nde kullanılan ancak Türkiye'de bulunmayan birçok ilacı içermesinden kaynaklandığ 1 düşünüldü. Ek olarak TIME-to-STOP kriterlerinin ilaç portföyünün ve önerilerdeki detayların daha kapsamlı olduğu gözlemlendi. TIME-to-STOP kriterlerinin dayanağı olarak Avrupa merkezli STOPP kriterleri alınmıştır. STOPP kriterleri ile Beers kriterlerinin karşılaştırıldığı Türkiye ile benzer ilaç piyasasına 
sahip birçok Avrupa ülkesindeki çalışmalarda da benzer şekilde potansiyel uygunsuz ilaç oranları STOPP kriterlerine göre daha yüksek oranda çıkmıştır ${ }^{15,16}$. Potansiyel uygunsuz ilaç kullanım oranının belirlenmesinin yanı sira TIME-to-STOP kriterlerinde daha bireyselleştirilmiş yaklaşımı görmekteyiz. Örneğin yeni oral antikoagülanlar da dahil olmak üzere nöroloji ve kardiyoloji ilaçlarında daha detaylı öneriler içermektedir. Dolayısıyla TIME-to-STOP kriterleri Türkiye için yaşlilarda tedavilerin düzenlenmesinde daha uygundur. Bu kriterlerin palyatif bakım ünitesi ya da bakım evi gibi yaşlılarla sıkça ilgilenilen birimlerde hasta bakım ve tedavi protokollerine eklenmesi ve klinisyenler ile sağlık bakım elemanlarının bu konudaki farkındalık düzeyinin arttırılması faydalı olacaktır. Polifarmasi ve olası advers etkilerin azaltılması için bu hastaların kullandıkları ilaçların akılcı olarak seçilmesi ve kontrollerde endikasyonu olmayan ilaçların tedavi listesinden çıkarılması gerekmektedir. Akut durumlarda acil servislerde kullanılan TIME-to-STOP kriterlerine göre potansiyel uygunsuz ilaç olarak değerlendirilen teofilin, nitrat, benzodiazepin gibi ilaçların hastanın rutin kontrollerinde endikasyon olmadı $\breve{g}_{1}$ takdirde reçetelenme kaskadından çıkarılması gerekmektedir. Diğer yandan bu hasta grubunun yaşam beklentisi kısa hastalar olması dolayısıyla normalde primer koruma açısından sıkça kullanılan aspirin veya statin gibi ilaçların reçetelenmesi uygun değildir.

Polifarmasiye maruz kalan hastaların TIME-to-STOP kriterlerine göre en az bir potansiyel uygunsuz ilaç kullandığının tespit edilmiş olması önemlidir. Bu durum beş ve daha fazla sayıda ilaç kullanan yaşlı bir bakım hastasılyla karşılaşıldığında öncelikli olarak dikkat edilmesi gereken bir husustur ve polifarmasi saptanan bir hastada yüksek olasılıkla bir veya daha fazla potansiyel uygunsuz ilaç olabileceğinin önemli bir göstergesidir. Yaşlı malignite hastalarındaki polifarmasi ve potansiyel uygunsuz ilaç kullanımının değerlendirildiği bir meta analizde 47 çalışma arasında sadece 3 çalışmada polifarmasi ve potansiyel uygunsuz ilaç kullanımı ile ilişki saptanmıştır ${ }^{17}$. Ancak polifarmasinin postoperatif komplikasyonlar, kemoterapi toksisitesi, fiziksel ve fonksiyonel yetersizlikle ilişkili olduğu bulunmuştur. Dolayısıyla potansiyel uygunsuz ilaç kullanımı olsun ya da olmasın polifarmasinin birçok advers etki ile ilişkili olduğu söylenebilir. Palyatif bakım ünitelerindeki polifarmasi durumunu değerlendiren bir çalışmada da kullanılan ilaç sayısı arttıkça hastanın ilaç uyumunun bozulduğu saptanmış$\operatorname{tır}^{18}$. Dolayısıyla kırılgan bir popülasyonu içeren yaşlı hasta grubunda polifarmasiden kaçınılmalı eğer endikasyon dahilinde ilaç reçete ediliyorsa hasta uyumunu arttırmak için muhakkak ilaç kullanımıyla ilgili eğitim verilmelidir.

Sonuç olarak, yaşlı, kırılgan bir hasta grubunun değerlendirildiği bu çalışmada polifarmasinin potansiyel uygunsuz ilaç kullanımını arttırabileceği görüldü.
TIME-to-STOP ve Beers gibi kriterlerin potansiyel uygunsuz ilaçları belirlemede başarılı bir araç olarak yaşlı bakımıyla ilgilenen birimlerin rutin uygulamasına alınması uygun olacaktır.

Etik Kurul Onay Bilgisi:

Onaylayan Kurul: ESOGÜ Tıp Fakültesi Etik Kurulu

Onay Tarihi: 01.08 .2021

Karar No: 2021-215

Araştırmacı Katkı Beyanı:

"Fikir ve tasarım: S.Ç.; Veri toplama ve işleme: S.Ç.; Analiz ve verilerin yorumlanması: S.Ç.; Makalenin önemli bölümlerinin yazılması: S.C..'

Çıkar Çatışması Beyanı:

Makale yazarlarının çıkar çatışması beyanı yoktur.

\section{Kaynaklar}

1. TÜİK Kurumsal. İstatistiklerle yaşlılar, 2020. Accessed 01.08.2021 https:// www.tuik.gov.tr.

2. World Health Organisation. Global Health and Ageing. 2011.

3. Yeşil Y, Kuyumcu ME. Polifarmasi. Klinik Gelişim 2012;25:18-23.

4. Maryann M. Fulton RN. Polypharmacy in the elderly: A literature review. J Am Acad Nurse Pract 2005;17:123-32.

5. Sirois C, Domingues NS, Laroche M-L, Zongo A, Lunghi C, Guénette L, et al. Polypharmacy definitions for multimorbid older adults need stronger foundations to guide research, clinical practice and public health. Pharmacy 2019;7(126):1-14.

6. Yürüyen M, Tevetoğlu IÖ, Tekmen Y, Polat Ö, Arslan İ, Okuturlar Y. Palyatif bakım hastalarında klinik özellikler ve prognostik faktörler. Konuralp Medical Journal 2018;10:74-80.

7. Kathleen Tschantz Unroe, Greg A. Sachs, Susan E. Hickman, Timothy E. Stump, Wanzhu Tu, Christopher M. Callahan. Hospice Use Among Nursing Home Patients. J Am Med Dir Assoc. $2013 ; 14$.

8. Stockl KM, Le L, Zhang Z, Harada AS. Clinical and economic outcomes associated with potentially inappropriate prescribing in the elderly. Am J Manag Care 2010;16:e1-10.

9. Lavan AH, Gallagher P, Parsons C, O’Mahony D. STOPPFrail (Screening Tool of Older Persons Prescriptions in Frail Adults with Limited Life Expectancy). Age Ageing 2017; 46:600-7.

10. 2019 American Geriatrics Society Beers Criteria ${ }^{\circledR}$ Update Expert Panel. American Geriatrics Society 2019 Updated AGS Beers Criteria ${ }^{\circledR}$ for Potentially Inappropriate Medication Use in Older Adults. J Am Geriatr Soc 2019;67:674-94.

11. Yang Y-X, Lewis JD, Epstein S, Metz DC. Long-term proton pump inhibitor therapy and risk of hip fracture. JAMA 2006;296:2947-53.

12. Clyne B, Smith SM, Hughes CM, Boland F, Bradley MC, Cooper JA, et al. Effectiveness of a multifaceted intervention for potentially inappropriate prescribing in older patients in primary care: a cluster-randomized controlled trial (OPTISCRIPT Study). Ann Fam Med 2015;13:545-53.

13. Demircan C, Hasanzade U. Polypharmacy and potential inappropriate drug use in the elderly admitted to the general internal medicine outpatient clinic. TJIM 2021;3(Suppl 1):46-8.

14. Sostres C, Carrera-Lasfuentes P, Lanas A. Non-steroidal antiinflammatory drug related upper gastrointestinal bleeding: types of drug use and patient profiles in real clinical practice. Curr Med Res Opin 2017;33:1815-20. 


\section{Yaşılılarda Polifarmasi ve Uygunsuz İlaç Kullanımı}

15. Awad A, Hanna O. Potentially inappropriate medication use among geriatric patients in primary care setting: a crosssectional study using the Beers, STOPP, FORTA and MAI criteria”. PLoS ONE 2019;14.

16. Blanco-Reina E, Valdellós J, Aguilar-Cano L, García-Merino MR, Ocaña-Riola R, Ariza-Zafra G, et al. 2015 Beers Criteria and STOPP v2 for detecting potentially inappropriate medication in community-dwelling older people: prevalence, profile, and risk factors. Eur J Clin Pharmacol 2019;75:1459-66.

17. Mohamed MR, Ramsdale E, Loh KP, Arastu A, Xu H, Obrecht $\mathrm{S}$, et al. Associations of polypharmacy and inappropriate medications with adverse outcomes in older adults with cancer: a systematic review and metaanalysis. Oncologist 2020;25:e94e108.

18. Gradalski T. Polypharmacy and Medication Errors on Admission to Palliative Care. Pol Arch Intern Med 2019;129:659-66. 
